\title{
Devekıran (Atraphaxis spinosa I.) Çalısının Büyüme Sürecinde Besin İçeriğinin Değişimi Üzerine Bir Araştırmaa
}

\author{
Bahattin Karakuş Bilal Keskin* \\ Iğdır Üniversitesi, Ziraat Fakültesi, Tarla Bitkileri Bölümü, Iğdır
}

Geliş tarihi (Received): 14.12.2017 Kabul tarihi (Accepted): 12.01.2018

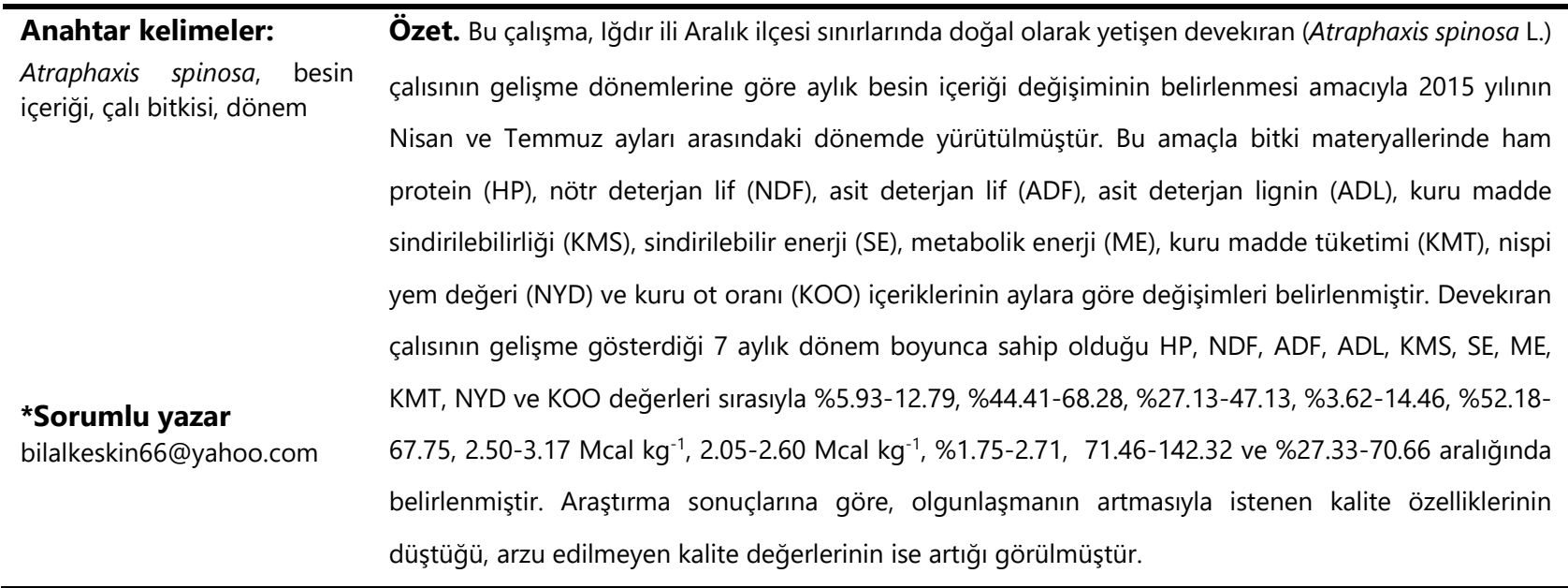

\section{Changes in Nutrient Content during the Growth Process of Goat's Wheat Manna (Atraphaxis spinosa I.)}

\footnotetext{
Keywords:

Atraphaxis spinosa, nutrient

content, shrub, period

\begin{abstract}
This study was conducted to determine the monthly nutrient content changes according to the developmental stages of the goat's wheat manna (Atraphaxis spinosa L.) which spontaneously grows in the Aralık district of Iğdır province between April and July in 2015. In this study, Crude protein (CP), Neutral Detergent Fiber (NDF), Acid Detergent Fiber (ADF), Acid Detergent Lignin (ADL), Dry Matter Digestibility (DMD), Digestible Energy (DE), Metabolizable Energy (ME), Dry Matter Intake (DMI), d Relative Feed Value (RFV) and Dry Matter Rate (DMR) contents of Goat's wheat manna was determined. Changes according to month CP, NDF, ADF, ADL, DMD, DE, ME, DMI, RFV and DMR value of goat's wheat manna were $5.93-12.79 \%, 44.41-68.28 \%, 27.13-47.13 \%, 3.62-14.46 \%, 52.18-67.75 \%, 2.50-3.17 \mathrm{Mcal}^{\mathrm{kg}}{ }^{-1}$, 2.05-2.60 Mcal kg-1, 1.75-2.71\%, 71.46-142.32 ve 27.33-70.66\%, respectively. According to the results of the research, with the maturation, the undesirable nutritional values increased, as the desired quality characteristics decreased.
\end{abstract}

ORCID ID (Yazar sırasına göre/By author order) 


\section{GíRiş}

Ülkemizde hayvanların kaliteli kaba yem ihtiyacı, çayır, mera ve tarla tarımı içerisinde yetiştirilen yem bitkileri olmak üzere üç önemli kaynaktan karşılanmaktadır. Doğal çayır meralar, geviş getiren hayvanların tabi besin kaynağı durumundadır. Doğal çayır ve mera alanlarında özellikle yaz ve sonbahar dönemlerinde yeterli miktarda ve kalitede kaba yem üretememektedir. Oysa odunsu (çalı ve ağaç) türler, otsu türlerin kuruduğu ve besin değerinin düştüğü yaz dönemlerinde ve gelişmenin durduğu kış dönemlerinde hayvanlara yem temin eden bir kaynak durumundadır (Temel and Tan 2011; Tan ve Temel 2012).

Doğal koşullarda yetişen pek çok çalı ve odunsu türün, kuvvetli ve derin olan kök sistemleri sayesinde kuraklığa toleransları yüksek olup, kültür bitkisinin gelişemediği alanlarda rahatça yetişebilmektedirler. Ayrıca çalı bitkileri hayvanlar için enerji, mineral, vitamin ve besin içeriği yönünden zengin kaba yem üretebilmektedirler (Ghazanfar et al., 2011; Temel and Tan 2011; Tan ve Temel 2012).

Bölge halkının büyük bir çoğunluğu geçimini hayvancılık yaparak sağlamaktadır. Yapılan hayvancılıkta ise hiç şüphesiz, kaliteli ve ucuz yem sağlayan çayır ve mera alanları önemli bir yer tutmaktadır. Ancak ığdır ili Aralık ilçesinde yaz aylarında sıcaklığın yüksek, yağışın düşük olması, gerek tarım alanlarında gerekse mera alanlarında pek çok otsu türün yetişmesini sınırlandırmaktadır. Iğdır ilinde çayır mera alanlarında 73.286 ton ve tarla alanlarında ekilen yem bitkilerinde 142.172 ton kuru ot elde edilmektedir. Iğdır ilinde 91.304 Büyük Baş Hayvan Birimi'nin ihtiyaç duyduğu kuru ot miktarı yıllık ortalama 333.260 ton'dur. İlin kaliteli kaba yem açığı yaklaşık olarak \%35.35'dir (Temel ve Şahin 2010).

Atraphaxis spinosa bitkisi kuzukulağıgiller (Polygonaceae) familyasındandır. Atraphaxis cinsinin sınıflandırılması türler arasındaki yoğun melezlemelere ve türlerin sahip oldukları morfolojik özelliklere bağlı olarak yüksek oranda çeşitlilik göstermektedir. Güneydoğu Avrupa, Güneybatı ve Merkez Asya, Güney Sibirya, Moğolistan ve Çin'de Atraphaxis cinsine bağlı yaklaşık 30 tür tanımlanmıştır (Pavlov 1936; Lovelius 1979). Atraphaxis spinosa 1.05 ile $1.45 \mathrm{~m}$ arasında bitki boyu, 2.95 ile $5.55 \mathrm{~m}$ genişliğinde ve 2.80 ile $4.46 \mathrm{~m}$ eninde bir alanı kapladığı belirlenmiştir (Karakuş 2016). Atraphaxis spinosa Ülkemizin Doğu ve Güneydoğu Anadolu bölgelerinde yayılış göstermektedir. Iğdır ili Aralık ilçesindeki erozyon sahalarında hakim çalı formasyonlarından biridir.

$\mathrm{Bu}$ çalışmada bölgenin erozyon, tuzlu, alkali ve kurak gibi ekstrem alanlarında yaygın olarak bulunan ve hayvanların otladığı devekıran çalısının gelişme dönemlerine bağlı olarak besin içeriğinin belirlenmesi hedeflenmiştir.

\section{MATERYAL VE METOT}

Bu çalışma, Iğdır ilinin Aralık ilçesi sınırları içinde yer alan rüzgâr erozyon sahasında yetişen devekıran (Atraphaxis spinosa L.) çalısının yıllık besin içeriği değişiminin belirlenmesi amacıyla 2015 yılında yürütülmüştür.

Iğdır ilinin iklim verileri Çizelge 1'de verilmiştir. Çizelge 1 incelendiğinde; 2015 yılı toplam yağış 302.4 $\mathrm{mm}$ 'dir.

Çizelge 1. Iğdır ilinin 2015 yılına ait bazı iklim özellikleri. Table 1. Some climate features of Iğdır province in 2015.

\begin{tabular}{|c|c|c|c|c|c|}
\hline \multirow[b]{2}{*}{ Aylar } & \multirow{2}{*}{$\begin{array}{l}\text { Aylık Toplam Yağış } \\
\text { (mm) }\end{array}$} & \multicolumn{3}{|c|}{ Sıcaklık Değerleri $\left({ }^{\circ} \mathrm{C}\right)$} & \multirow{2}{*}{$\begin{array}{c}\text { Aylık Ort. } \\
\text { Nispi Nem (\%) }\end{array}$} \\
\hline & & Min. & Ort. & Max. & \\
\hline Ocak & 2.2 & -9.8 & 1.2 & 15.6 & 63.3 \\
\hline Şubat & 4.4 & -4.8 & 6.8 & 15.8 & 59.5 \\
\hline Mart & 52.0 & -4.7 & 11.0 & 20.4 & 50.8 \\
\hline Nisan & 44.1 & 3.5 & 16.4 & 29.9 & 47.7 \\
\hline Mayıs & 41.5 & 7.0 & 21.3 & 32.2 & 52.9 \\
\hline Haziran & 27.8 & 12.5 & 28.5 & 37.8 & 40.0 \\
\hline Temmuz & 0.3 & 16.2 & 31.8 & 38.8 & 33.6 \\
\hline Ağustos & 14.3 & 13.6 & 30.2 & 41.4 & 40.7 \\
\hline Eylül & 1.4 & 10.7 & 27.2 & 35.6 & 42.4 \\
\hline Ekim & 96.2 & 4.8 & 16.6 & 27.3 & 71.3 \\
\hline Kasım & 4.5 & -3.6 & 9.2 & 18.3 & 66.0 \\
\hline Aralık & 13.7 & -7.8 & 1.5 & 11.3 & 68.8 \\
\hline Top/Ort. & 302.40 & & 16.81 & & 53.08 \\
\hline Uzun Yıl Ort. & 257.6 & & 11.6 & & 63.00 \\
\hline
\end{tabular}


Sıcaklık açısından bakıldığında en düşük sıcaklık $9.8^{\circ} \mathrm{C}$ ile Ocak ayı en yüksek sıcaklık $41.4^{\circ} \mathrm{C}$ ile Ağustos ayında yıllık sıcaklık ortalaması ise $16.81^{\circ} \mathrm{C}^{\prime}$ dir. Nispi nem olarak incelendiğinde 2015 yılı ortalaması \% 53.08'dir. Araştırmanın yürütüldüğü Nisan-Ekim dönemlerinde toplam yağış miktarı $225.6 \mathrm{~mm}$, ortalama sıcaklık $23.01{ }^{\circ} \mathrm{C}$ ve ortalama nispi nem \%46.94 olarak gerçekleşmiştir. Uzun yıllar ortalamasına göre Iğdır ilinin yıllık yağış miktarı (257.6 $\mathrm{mm}$ ) düşük, sıcaklık derecesi ise ortalama $11.6{ }^{\circ} \mathrm{C}$ 'dir. $\mathrm{Bu}$ verilere göre Iğdır ili Türkiye'nin en kurak yerleri arasında kalmaktadır (Anonim 2015).

Araştırma alanında $0-40 \mathrm{~cm}$ toprak derinliğinde alınan toprak örnekleri Iğdır Üniversitesi Ziraat Fakültesi Laboratuvarlarında analiz edilmiş ve elde edilen analiz sonuçları Çizelge 2'de verilmiştir. Çizelge 2 incelendiğinde, denemenin kurulduğu toprakların tuzsuz, orta alkali karakterde, organik madde içeriği çok az, kireç içeriği orta, fosfor içeriği yüksek, azot içeriği çok az ve potasyum içeriğinin ise yüksek olduğu görülmüştür (Kaçar, 1972).

Devekıran (Atraphaxis spinosa I.) bitkisinde NisanEkim ayları arasında 7 ay süreyle, her ayın sonunda alınan bitki materyallerinde (sap + yaprak) HP, NDF, ADF, ADL, KMS, SE, ME, KOO, KMT ve NYD özellikleri incelenmiştir. Bitki kalite özelliklerinin belirlenmesi amacıyla bitkinin sap + yaprak kısımlarında hayvanların otlatma alışkanlıkları taklit edilerek örnekler alınmıştır. Çalı öbeklerinin olduğu deneme alanı 3 parçaya bölünmüş ve her biri bir blok olarak ele alınmıştır. Araştırmanın tek faktörü olan örnek alım zamanları (aylar)'nın istatistiksel analizleri tesadüf blokları deneme desenine göre yapılmıştır. Ayrıca blok olarak belirlenen alanda bitkilerin besin içeriklerini daha iyi yansıtabilmesi için 5 çalı öbeğinde bitki örneği alınmış ve karıştırılarak tek örnek oluşturulmuştur.

Elde edilen örneklerde ham protein oranı (Kacar, 1972); NDF , ADF ve ADL oranları (Van Soest et al., 1991); KMS (Kuru madde sindirilebilirliği)=88.9-(0.779 x \%ADF) (Oddy et al., 1983); SE (Sindirilebilir enerji Mcal kg-1) $=0.27+0.0428 \times(\% \mathrm{KMS})$ (Fonnesbeck et al., 1984); ME (Metabolik enerji Mcal kg-1) $=0.821 \times \mathrm{SE}$ (Mcal kg-1) (Khalil et al., 1986); KMT (Kuru madde tüketimi) oranı = 120 / (\%NDF) (Sheaffer et al., 1995); NYD (Nispi yem değeri) $=($ KMS $x$ KMT) /1.29 Sheaffer et al. (1995)'e göre yapılmıştır. Kuru ot oranını belirlemek için ise her ay alınan bitki örnekleri açık havada kurutulduktan sonra $70^{\circ} \mathrm{C}^{\prime}$ ye ayarlı kurutma fırınında kurutularak bulunmuştur. Örnekler kurutma fırınında ağırlıkları sabitleşinceye kadar bekletilmiş ve tartılmıştır. Kurutulan ot örneklerinin ağırlığı yaş ot örneklerine oranlanıp kuru ot oranları tespit edilmiştir.

Denemede elde edilen sonuçların varyans analizleri ve ortalamaların Duncan çoklu karşılaştırma testi SPSS paket programında yapılmıştır (SPSS 1991).

\section{BULGULAR VE TARTIŞMA}

Devekıran çalısının gelişme gösterdiği Nisan-Ekim ayları arasındaki besin içerikleri Çizelge 3'de verilmiştir.

Çizelge 2. Deneme alanına ait toprak özellikleri.

Table 2. Soil properties of the experiment area.

\begin{tabular}{ccccccc}
\hline pH (1:2.5 & EC (dS $\left.\mathbf{~ m}^{-1}\right)$ & Kireç (\%) & $\begin{array}{c}\text { Organik } \\
\text { Madde(\%) }\end{array}$ & Toplam Azot (\%) Fosfor (ppm) & Potasyum (\%) \\
\hline 8.07 & 1.41 & 8.71 & 0.17 & 0.008 & 29.39 & 0.20 \\
\hline
\end{tabular}

Çizelge 3. Farklı gelişme dönemlerinde devekıran (Atraphaxis spinosa I.) çalısının besin maddesi içerikleri. Table 3. Nutrient content of Goat's Wheat Manna(Atraphaxis spinosa l.) during different periods of development.

\begin{tabular}{|c|c|c|c|c|c|c|c|c|c|c|}
\hline Aylar & $\begin{array}{l}\text { HP } \\
(\%)\end{array}$ & $\begin{array}{l}\text { NDF } \\
\text { (\%) }\end{array}$ & $\begin{array}{l}\text { ADF } \\
\text { (\%) }\end{array}$ & $\begin{array}{l}\text { ADL } \\
\text { (\%) }\end{array}$ & $\begin{array}{l}\text { KMS } \\
\text { (\%) }\end{array}$ & $\begin{array}{l}\text { SE } \\
\left(\text { Mcal kg-1) }^{-1}\right.\end{array}$ & $\begin{array}{l}\text { ME } \\
\left(\text { Mcal } \mathbf{k g}^{-1}\right)\end{array}$ & $\begin{array}{l}\text { KMT } \\
\text { (\%) }\end{array}$ & NYD & $\begin{array}{l}\text { KOO } \\
\text { (\%) }\end{array}$ \\
\hline Nisan & $12.79 \mathrm{a}$ & $44.41 \mathrm{~d}$ & $27.13 \mathrm{c}$ & $3.62 \mathrm{~b}$ & $67.75 \mathrm{a}$ & $3.17 \mathrm{a}$ & $2.60 \mathrm{a}$ & $2.71 \mathrm{a}$ & $142.32 \mathrm{a}$ & $27.33 \mathrm{f}$ \\
\hline Mayıs & 9.37 b & $51.33 \mathrm{c}$ & $38.03 \mathrm{ab}$ & $9.35 \mathrm{a}$ & $59.27 b c$ & $2.80 \mathrm{bc}$ & $2.30 \mathrm{bc}$ & $2.34 \mathrm{~b}$ & $107.71 \mathrm{~b}$ & $31.33 \mathrm{e}$ \\
\hline Haziran & 8.20 bc & $62.28 \mathrm{~b}$ & $44.45 \mathrm{ab}$ & $10.40 \mathrm{a}$ & 54.27 bc & $2.59 \mathrm{bc}$ & $2.12 b c$ & $1.93 \mathrm{~cd}$ & $81.15 \mathrm{~cd}$ & $61.33 \mathrm{~b}$ \\
\hline Temmuz & $5.93 d$ & $68.49 a$ & $47.13 \mathrm{a}$ & $14.46 \mathrm{a}$ & $52.18 \mathrm{c}$ & $2.50 \mathrm{c}$ & $2.05 \mathrm{c}$ & $1.75 \mathrm{~d}$ & $71.46 \mathrm{~d}$ & $70.66 \mathrm{a}$ \\
\hline Ağustos & $8.20 b c$ & $59.69 \mathrm{~b}$ & $39.33 \mathrm{ab}$ & $11.82 \mathrm{a}$ & $58.25 \mathrm{bc}$ & $2.76 \mathrm{bc}$ & $2.26 \mathrm{bc}$ & $2.01 \mathrm{c}$ & $90.75 \mathrm{bc}$ & $69.66 \mathrm{a}$ \\
\hline Eylül & $8.13 b c$ & 56.41 bc & $41.27 \mathrm{ab}$ & $12.44 \mathrm{a}$ & 56.74 bc & $2.69 b c$ & $2.21 b c$ & $2.13 \mathrm{bc}$ & 94.20 bc & $58.66 \mathrm{~b}$ \\
\hline Ekim & $6.95 \mathrm{~cd}$ & 60.72 b & $35.40 \mathrm{bc}$ & $13.76 \mathrm{a}$ & $61.32 \mathrm{ab}$ & $2.89 \mathrm{ab}$ & $2.37 a b$ & $1.97 \mathrm{c}$ & $93.83 \mathrm{bc}$ & $50.33 \mathrm{c}$ \\
\hline Ort. & 8.52 & 57.62 & 38.96 & 10.84 & 58.55 & 2.78 & 2.28 & 2.12 & 97.35 & 52.75 \\
\hline F Değerleri & $15.67^{* *}$ & $17.74^{* *}$ & $3.82^{*}$ & $4.56^{*}$ & $3.82^{*}$ & $3.82^{*}$ & $3.82^{*}$ & $21.91^{* *}$ & $16.68^{* *}$ & $210.46^{* \star}$ \\
\hline CV Değeri & 11.20 & 5.60 & 14.84 & 27.26 & 7.69 & 6.95 & 6.90 & 5.47 & 9.95 & 4.00 \\
\hline
\end{tabular}

** \%1 ihtimal düzeyinde çok önemli, * \%5 ihtimal düzeyinde önemlidir. Benzer harfli olanlar arasındaki fark önemli değildir. 
Bitkinin gelişme dönemlerine (aylara) göre $\mathrm{HP}$, NDF, KMT, NYD, KOO, ADF, ADL, KMS, SE ve ME değerlerindeki değişim önemli bulunmuştur. Bitkinin aktif olarak gelişim gösterdiği dönem boyunca sahip olduğu en düşük ve en yüksek HP oranı \%5.93 ve 12.79, NDF \%51.33 ve 68.49, ADF \%27.13 ve 47.13, ADL $\% 3.62$ ve 14.46 , KMS \%52.18 ve 67.75 , SE 2.50 ve 3.17 Mcal kg-1, ME 2.05 ve 2.60 Mcal kg-1, KMT \%1.75 ve 2.71, NYD 71.46 ve 142.32 ve KOO \%27.33 ve 70.66 olarak bulunmuştur.

Farklı çalı türlerinin besin içeriğinin belirlenmesi amacıyla birçok çalışma yürütülmüştür. Örneğin; Parlak et al. (2011) tarafından yürütülen bir çalışmada kermes meşesi (Quercus coccifera) çalısının yılın 12 ayı süresince alınan örneklerinde HP içeriğini 56.3-136.3 g $\mathrm{kg}^{-1}$, NDF'yi 298.0-649.3 $\mathrm{g} \mathrm{kg}^{-1}$, ADF'yi 224.9-523.7 g $\mathrm{kg}^{-1}, \mathrm{ADL}$ değerini $101.6-257.7 \mathrm{~g} \mathrm{~kg}^{-1}, \mathrm{KMS}$ oranını \%43.6-70.8 ve ME değerlerini ise 1.76-2.71 Mcal kg-1 olarak belirlemişlerdir.

Yurtseven (2011) Sakız geveni (Astragalus gummifera)'nin toprak üstü organlarının NYD, KMS ve KMT değerlerini sırayla 56.03, \%43.5 ve \%1.66 olarak belirlenmiş ve bu değerlerin otsu türlere göre oldukça yüksek olduğunu belirtmiştir.

Illkbahar aylarında devekıran çalısının HP, KMS, SE, $M E, K M T$ ve NYD içerikleri yüksek (sırasıyla \%12.79, \%67.75, 3.17 Mcal kg-1, 2.60 Mcal kg-1, \%2.71 ve 142.32), NDF, ADF, ADL ve KOO oranları ise düşük (sırasıyla \%44.41, \%27.13, \%3.62 ve \%27.33) olmuştur. Ancak olgunlaşmayla birlikte arzu edilen kalite özellikleri azalmış, kaliteyi olumsuz etkileyen değerler artmıştır. Buna göre en yüksek HP (\%12.79), KMS (\%67.75), SE (3.17 Mcal kg-1), ME (2.60 Mcal kg-1), KMT (\%2.71) ve NYD (142.32) oranları Nisan ayında, en düşük HP (\%5.93), KMS (\%52.18), SE (2.50 Mcal kg-1), ME (2.05 Mcal kg-1), KMT (\%1.75) ve NYD (71.46) değerleri ise Temmuz ayında belirlenmiştir (Çizelge 3). Oysa NDF (\%68.49), ADF (\%47.13), ADL (\%14.46) ve KOO (\%70.66) oranları en yüksek Temmuz ayında, en düşük NDF (\%44.41), ADF (\%27.13), ADL (\%3.62) ve KOO (\%27.33) oranları ise Nisan ayında belirlenmiştir. Genellikle ilk aylara göre Temmuz ve Ekim aylarında besin kaybı daha fazla gerçekleşmiştir. Temmuz ayında sıcaklık değerlerinin diğer aylara göre yüksek olması, en düşük yağış miktarının ve en düşük aylık ortalama nispi nemin Temmuz ayında görülmesi nedeniyle bu ayda bitki gelişmesinin zayıfladığı ve bunun sonucunda HP oranında azalma olduğu düşünülmektedir.

Bitkilerin olgunlaşmasıyla birlikte yaşlanan hücrelerde lifli bileşiklerin birikimi genç hücrelere oranla daha fazla bulunur (Lyons et al., 1999). Bitkiler olgunlaştıkça NDF ve ADF gibi hücre duvarı bileşikleri artmakta ve bitkilerde arzu edilen ham protein gibi bileşikler ise azalmaktadır (Haddi et al., 2003; Akbağ et al., 2014; Parissi et al., 2005). Bitki gelişmesinin ileri dönemlerinde sap oranı artmakta, yaprak oranı ise azalmaktadır (Frost et al., 2008). Bitkinin diğer organlarına göre, saplar daha fazla selüloz içermektedir (Buxton 1996; Claessens et al., 2005). Çalı bitkisi (kermes meşesi) üzerinde yapılan bir çalışmada, bitkinin olgunlaşmasıyla birlikte daha yüksek ADF ve NDF, daha düşük HP içeriğine sahip olduğunu belirlenmiştir (Papachristou et al., 2005).

Otsu türlerde olduğu gibi çalı ve ağaç türlerin de gelişme dönemlerine bağlı olarak yapraklarındaki besin içerikleri değişmektedir. Değişik ekolojik şartlarda yürütülen pek çok çalışmada odunsu (çalı ve ağaç) türlerin olgunlaşmasıyla birlikte $\mathrm{HP}, \mathrm{KOO}, \mathrm{ME}$ içeriklerinin azaldığı, NDF, ADF, ADL ve kül içeriklerinin ise arttığı belirtilmiştir (Papachristou and Papanastasis 1994; Ataşoğlu et al., 2010; Parlak et al., 2011; Tan ve Temel 2012).

Bitkinin ilkbaharda büyümeye başlaması ile birlikte genç hücre sayısı artmakta ve genç hücrelerin içerdiği protein miktarı diğer bileşiklere göre daha fazla olmaktadır. (Kacar ve ark., 2006). Ancak sonbahar ve yaz dönemlerinde bitkilerin içerdiği HP içeriği düşmekte, lif ve kül içeriği ise artmaktadır (Mountousis et al., 2008; Ataşoğlu et al., 2010). Yine bitkilerin besleme değerini etkileyen en önemli unsurlardan birisi de örnekleme zamanıdır (Buxton et al., 1985; Kamalak et al., 2005a,b). Genellikle bitkilerde gelişme dönemi ilerledikçe kuru madde ve ham selüloz oranının arttığı, buna karşılık ham proteinin azaldığı bildirilmiştir (Akyıldız 1986; Ergül 1988). Ayrıca bitkilerin olgunlaşmasıyla sap/yaprak oranı yükselmekte (Frost et al., 2008) ve bunun sonucunda NDF, ADF ve ADL bileşikleri artmakta, ham protein bileşikleri ise azalmaktadır (Parissi et al., 2005).

Genellikle odunsu türlerin HP içeriği daha düşük, lif ve kül içeriği ise daha yüksektir. Yapılan çalışmalarda protein içeriklerinin ilkbahar dönemlerinde yüksek olduğu, yaz dönemlerinde ise azaldığı belirlenmiştir (Gonzalez-Andres and Ceresuela 1998; Papachristou et al., 2005). Çalı ve ağaç türlerinde ilkbahar büyüme döneminde protein içeriğinin yüksek olduğu, bitkinin olgunlaşmasıyla birlikte kuru madde verimi ve hücre duvarı içerikleri artmakta ve buna paralel olarak besin kaybı yaşandığı tespit edilmiştir (Papachristou et al., 2005; Kamalak 2006). Bundan dolayı bu türler özellikle yaz dönemlerinde daha yüksek lif ve kül, düşük ham protein içeriğine sahiptirler (Ataşoğlu et al., 2010). 


\section{SONUÇ}

Iğdır ili Aralık ilçesinde rüzgâr erozyonun yoğun olduğu alanlarda yaygın olarak yetişen devekıran çalııı ile yürütülen bu çalışmada, olgunlaşmanın ilerlemesiyle birlikte bitkilerdeki istenen kalite özelliklerinin düştüğü, arzu edilmeyen besin değerlerinin ise arttığı görülmüştür. Özellikle büyüme başlangıcına göre Temmuz ve Ekim aylarındaki arzu edilen besin içerikleri daha düşük olmuştur.

Sonuç olarak, devekıran çalısının gelişme gösterdiği dönemlerde bu alanlardan faydalanan hayvanlara iyi bir yem kaynağı olabileceği belirlenmiştir. Illkbahar dönemlerinde ham protein oranının yüksek, NDF, ADF ve ADL miktarlarının düşük olması nedeniyle, bu dönemdeki otlatmaların hayvanların bu yemden yararlanması yükseltecektir. Ayrıca ekstrem iklim ve toprak şartlarının yaşandığı yerlerde otsu türlerin sarardığı, yeterli miktar ve kalitede yem materyalinin temin edilemediği ve ortamda otlanacak yem materyalinin kalmadığı dönemlerde de hayvanlar için bir yem kaynağı olduğu ortaya konulmuştur.

\section{TEŞEKKÜR}

Bu araştırma, Iğdır Üniversitesi Bilimsel Araştırma Projeleri Koordinasyon Birimi tarafından 2016-FBE-L01 nolu proje olarak desteklenmiş olup katkılarından dolayı teşekkür ederiz.

\section{KAYNAKLAR}

Anonim, 2015. Iğdır Meteoroloji ì Müdürlüğü, Iğdır.

Akbağ HI., Türkmen OS., Baytekin H and Yurtman IY., 2014. Effects of harvesting time on nutritional value of hydroponic barley production. Turkish Journal of Agricultural and Natural Sciences Special Issue, 2: 17611765.

Akyıldız AR., 1986. Yemler Bilgisi ve Teknolojisi. Ankara Üniv. Zir. Fak. Yayınları, Yayın No:974, Ders Kitabı No:286, Ankara.

Ataşoğlu C., Şahin S., Canbolat Ö and Baytekin H., 2010. The effect of harvest stage on the potential nutritive value of kermes oak (Quercus coccifera) leaves. Livestock Research for Rural Development 22(2):182-185.

Buxton DR., Homstein JS., Wedin WF and Marten GC., 1985. Forage quality in stratified canopies of alfalfa, birdsfood trefoil and red clover. Crop Science, 25: 429-435.

Buxton DR., 1996. Quality-related characteristics of forages as influenced by plant environment and agronomic factors. Animal Feed Science and Technology, 59: 37-49.

Claessens A., Michaund R., Belanger G and Mather DE., 2005. Leaf and stem characteristics of timothy plants divergently selected for the ratio of lignin to cellulose. Crop Science, 45: 2425-2429.

Ergül M., 1988. Yemler Bilgisi ve Teknolojisi. Ege Üniversitesi Ziraat Fakültesi Yayınları, Yayın No:487, Ege Üniversitesi Basımevi, İzmir.

Fonnesbeck PV., Clark DH., Garret WN and Speth CF., 1984. Predicting energy utilization from alfalfa hay from the Western Region. Proceeding of American Society of Animal Sciences (Western Section), 35: 305-308.

Frost RA., Wilson LM., Launchbaugh KL and Hovde EM., 2008. Seasonal change in forage value of rangeland weeds in Northern Idaho. Invasive Plant Science and Management, 1(4): 343-351.

Ghazanfar S., Latif A., Mirza IH and Nadeem MA., 2011. Macro-minerals concentrations of major fodder tree leaves and shrubs of district Chakwal, Pakistan. Pakistan Journal of Nutrition, 10(5): 480-484.

Gonzalez-Andres F. and Ceresuela JL., 1998. Chemical composition of some Iberian Mediterranean leguminous shrubs potentially useful for forage in seasonally dry areas. New Zealand Journal of Agricultural Research, 41:139-147.

Haddi ML., Filacorda S., Meniai K., Rollin F and Susmel P., 2003. In vitro fermentation kinetics of some halophyte shrubs sampled at three stages of maturity. Animal Feed Science and Technology, 104: 215-225.

Kacar B., 1972. Bitki ve Toprağın Kimyasal Analizleri: II. Bitki Analizleri. Ankara Üniversitesi Ziraat Fakültesi Yayını No:453, 464 s, Ankara.

Kacar B., Katkat AV ve Öztürk Ş., 2006. Bitki Fizyolojisi (2. Baskı). Nobel Yayın Dağıtım, s:563, Ankara.

Kamalak A., 2006. Determination of nutritive value of a native grown shrub, Glycyrrhiza glabra L. Using in vitro and in situ measurements. Small Ruminant Research, 64: 268278.

Kamalak A., Canpolat O., Gurbuz Y., Erol A and Ozay O., 2005a. Effect of maturity stage on chemical composition in vitro and in situ dry matter degradation of tumbleweed hay (Gundelia tournefortii L.). Small Ruminant Research, 58; 149-156.

Kamalak A., Canbolat O., Gurbuz Y., Ozkan CO and Kızılsimsek M., 2005b. Determination of nutritive value of wild mustard, Sinapsis arvensis harvested at different maturity stages using in situ and in vitro measurements. Asian-Australasian Journal of Animal Sciences, 18(9): 1249-1254.

Karakuş B., 2016. Marjinal alanlarda yetişen devekıran (Atraphaxis spinosa L.) çalısının yıllık besin içeriği değişimi ve toprak özelliklerine etkisi. Yüksek Lisans Tezi, Iğdır Üniversitesi Fen Bilimleri Enstitüsü, Iğdır. 
Khalil JK., Sawaya WN and Hyder SZ., 1986. Nutrient composition of Atriplex leaves grown in Saudi Arabia. Journal of Range Management, 39: 104-107.

Lovelius OL., 1979. Synopsis generic Atraphaxis L. (Polygonaceae). Novitates systematicae plantarum vascularium, 1978, Nauka, Leningrad 15:114-128 (in Russian).

Lyons RK., Machen RV and Forbes TDA., 1999. Why Range Forage Quality Changes, Texas Agrilife Extension Texas A and $\mathrm{M}$ System, B-6036.

Mountousis J., Papanikolaou K., Stanogias G., Chatzitheodoridis F and Roukos C., 2008. Seasonal variation of chemical composition and dry matter digestibility of rangelands in NW Greece. Journal of Central European Agriculture, 9(3): 547- 556.

Oddy VH., Robards GE and Low SG., 1983. Prediction of in vivo dry matter digestibility from the fiber nitrogen content of a feed. In: Robards, G.E., Packham, R.G. (Eds.), Feed Information and Animal Production. Commonwealth Agricultural Bureau, Farnham Royal, UK, pp. 395-398.

Parlak AO., Gokkus A., Hakyemez B and Baytekin H., 2011. Forage yield and quality of Kermes oak and herbaceous species throughout a year in Mediterranean zone of western Turkey. Journal of Food, Agriculture \& Environment, 9(1):510-515.

Papachristou TG and Papanastasis VP., 1994. Forage value of Mediterranean deciduous woody fodder species and its implication to management of silvo-pastoral systems for goats. Agroforestry Systems, 27: 269-282.

Papachristou TG., Platis PD and Nastis AS., 2005. Foraging behaviour of cattle and goats in oak forest stands of varying coppicing age in Northern Greece. Small Ruminant Research, 59: 181-189.
Parissi ZM., Papachristou TG and Nastis AS., 2005. Effect of drying method on estimated nutritive value of browse species using an in vitro gas production technique. Animal Feed Science and Technology, 123-124(1): 119128.

Pavlov NV., 1936. Atraphaxis L. In: Komarov VL (ed) Flora URSS. URSS Acad. Sci. Publ. Moscow, Leningrad. 5:501527 (in Russian).

Sheaffer CC., Peterson MA., Mccalin M., Volene JJ., Cherney JH., Johnson KD., Woodward WT and Viands DR., 1995. Acid Detergent Fiber, Neutral Detergent Fiber Concentration and Relative Feed Value. North American Alfalfa Improvement Conference, Minneapolis.

SPSS Inc., 1991. Statistical Package For The Social Sciences (SPSS/PC+). Chicago, IL.

Tan M ve Temel S., 2012. Alternatif Yem Bitkileri. Atatürk Üniversitesi Ziraat Fakültesi Ders Yayınları No: 246, 195207, Erzurum.

Temel S ve Şahin K., 2010. Iğdır ilinde Yem Bitkilerinin Mevcut Durumu, Sorunları ve Çözüm Önerileri. Yüzüncü Yıl Üniversitesi Tarım Bilimleri Dergisi, 21(1):64-72.

Temel S and Tan M., 2011. Fodder values of shrub species in maquis in different altitudes and slope aspects The Journal of Animal and Plant Sciences (The JAPS), 21(3): 508-512.

Van Soest PJ., Robertson JD and Lewis BA., 1991. Methods for dietary fiber, neutral detergent fiber and non-starch polysaccharides in relation to animals nutrition. Journal of Dairy Science, 74: 3583-3597.

Yurtseven S., 2011. Determination of the feed values of çaşir (Prangos ferulacea) and goat's thorn (Astragalus gummifera) located in natural plant flora of the southeastern anatolia region. Journal of the Faculty of Veterinary Medicine, Kafkas University, 17(6): 909-915. 